\title{
The effect of canopy position on growth and mortality in mixed sapling communities during self-thinning
}

\author{
M. Dekker · U. Sass-Klaassen · J. den Ouden • \\ P. W. Goedhart
}

Received: 3 March 2008/Revised: 17 February 2009/ Accepted: 23 May 2009/Published online: 8 July 2009

(C) The Author(s) 2009. This article is published with open access at Springerlink.com

\begin{abstract}
This research investigates how species in the sapling phase differ in growth and survival depending on light availability (as estimated by canopy position) by means of tree-ring analysis and modelling mortality. We harvested 120 live and 158 dead saplings in self-thinning communities consisting of Silver birch (Betula pendula Roth.), Scots pine (Pinus sylvestris L.), Japanese larch (Larix kaempferi Carr.) and Douglas fir (Pseudotsuga menziesii Mirb. Franco) in the Netherlands. Results are evaluated within the framework of a trade-off between high-light growth and low-growth survival. Radial growth, measured at ground level, generally declined over time. In addition, a decreasing light availability further reduced growth in all species except Douglas fir. Trees died when radial growth was reduced to about $0.5 \mathrm{~mm} \mathrm{year}^{-1}$. Mortality in all species except Scots pine was significantly related to recent growth, but mortality curves were not different. The light-demanding Silver birch and Japanese larch differed from the shade-tolerant Douglas fir in both high-light growth and low-growth mortality, in line with a growth-survival trade-off. The light-demanding Scots pine
\end{abstract}

Communicated by K. Puettmann.

M. Dekker · U. Sass-Klaassen · J. den Ouden ( $\square)$

Forest Ecology and Forest Management Group,

Centre for Ecosystem Studies,

Wageningen University and Research Centre,

P.O. Box 47, 6700 AH Wageningen, The Netherlands

e-mail: jan.denouden@wur.nl

M. Dekker

e-mail: m.dekker@adignis.nl

P. W. Goedhart

Biometris, Wageningen University and Research Centre,

P.O. Box 100, 6700 AC Wageningen, The Netherlands did not fit this pattern as it was unable to transfer high radial growth into height gain, leaving it in suppressed canopy positions. This indicates the importance of height growth in the growth-survival trade-off. Differences in mortality probabilities affect the potential for coexistence, however, in all species also fast-growing individuals died suggesting additional factors causing mortality during selfthinning, other than direct competition for light.

Keywords Competition for light . Tree-ring analysis . Saplings - European temperate forest .

Growth-survival trade-off

\section{Introduction}

Forest gap regeneration is rarely homogenous, and saplings competing within a gap can differ considerably in size. Size differences between individuals result from differences in time of establishment, neighbourhood density and microsite conditions (Huston 1994; Oliver and Larson 1996). Size differences between species additionally result from genotypic differences in growth rate and slenderness (King 1994; Westoby 1998; Poorter et al. 2003).

Interspecific differences in height are particularly important as taller individuals are able to gain a disproportional part of the incident light (Franco and Kelly 1998; Schwinning and Weiner 1998). This can have a critical effect on growth and survival depending on a species' light demand (Kohyama 1993; Grime 2001; Sterck et al. 2003). Therefore, both a species' growth rate as well as its shade-tolerance (or better: shade persistence) are important factors in the interspecific competition for light. Stable coexistence has been proposed to occur along a trade-off between high-light growth and low-light survival (Kobe et al. 1995; Reich et al. 
2003; Kitajima and Poorter 2008). This growth-survival trade-off stems from a trade-off in carbon allocation to either growth on the one hand, or storage and defence on the other hand (Poorter and Kitajima 2007). This trade-off is found in both tropical (Kitajima 1994) and temperate tree species (Walters and Reich 1996).

Previous research in self-thinning sapling communities in the Netherlands has shown that the studied species already vertically stratify in the gap building phase (Dekker et al. 2007). The vertical stratification led to a strong competition for light which affected species differently, depending on light demand (Dekker et al. 2008). Other studies also found that morphological differentiation between species affects competitive relations (Sterck and Bongers 2001; Kohyama et al. 2003; Poorter et al. 2003; Osada et al. 2004).

These previous results appear in line with a growthsurvival trade-off. However, it remains unclear howunder uncontrolled field conditions-light availability influences radial growth, and how persistent low growth is related to mortality. Field conditions, contrary to controlled experimental conditions, incorporate unpredictable environmental fluctuations that occur over time, and multiple stressors, such as competition, nutrient deficiencies and drought. If the component species of a dynamic plant community still consistently differ in their growth and survival under field conditions, then this could potentially allow their coexistence through niche partitioning, as proposed by the growth-survival trade-off.

For example, Lin et al. (2002) found a growth-survival trade-off under field conditions for saplings of seven cooccurring sub-tropical tree species. Niches overlapped, but a growth-survival trade-off did contribute to light gradient partitioning and coexistence. Seiwa (2007) reported similar results for seedling growth and survival in relation to gap size in a temperate forest. His results also suggested a partitioning of the available light, leading to species coexistence. In a tropical forest, Poorter and Arets (2003) showed niche separation for saplings of 10 species of trees as a result of differences in growth and survival, allowing their coexistence in a narrow range of light environments. Often, however, field data on which results are based span only a few years, leaving out the long-term effects of competition and environmental fluctuations on growth and survival. As long-term chronosequences are laborious and costly to collect, treering studies can be used as an alternative to analyse radial growth dynamics and survival of saplings in relation to light (Kobe et al. 1995 and ensuing publications).

The objective of this research is to investigate (1) whether saplings of species with different light demand differ in their growth response to light availability, and (2) whether persistent low growth enhances the chance of mortality. To do so, we chose a retrospective approach by means of tree-ring analysis. The study was conducted in dense sapling communities under high-competitive stress, as well as under additional sources of environmental stress. We focussed on the specific contribution of canopy position to growth and survival in four species that dominate the natural regeneration in gaps in Douglas fir forests in the Netherlands. These are Silver birch Betula pendula (Roth.), Scots pine Pinus sylvestris (L.), Japanese larch Larix kaempferi (Carr.) and Douglas fir Pseudotsuga menziesii (Mirb. Franco). The two latter species are non-indigenous, and the natural development of communities of these four species beyond the gap building phase is unknown so far. We will specifically address the following questions: (1) how does radial growth over time vary with light availability; (2) what are interspecific differences in growth responses depending on a species' light-demand; and (3) how do species differ in the probability of mortality depending on radial growth. We hypothesise that lightdemanding species show a stronger (and negative) response to decreasing light availability and have a higher probability of mortality under reduced growth conditions compared to shade-tolerant species.

\section{Materials and methods}

\section{Species and study sites}

Our four focal species differ in light demand during their juvenile phase, ranging from the extremely light-demanding Silver birch and Scots pine, to the comparatively shadetolerant Douglas fir (Mayer 1992; Burschel and Huss 1997). Japanese larch is intermediate between these extremes (CABI 2005; Dekker et al. 2007).

We collected our data in the densely forested Veluwe area, centrally located in the Netherlands. Our research area was the southern part of the Hoge Veluwe National Park $\left(52^{\circ} 2^{\prime} 14^{\prime \prime} \mathrm{N}, 5^{\circ} 50^{\prime} 41^{\prime \prime} \mathrm{E}\right)$. In this area we located five sites with a dense and fully-stocked regeneration in canopy gaps (i.e. gap diameter in excess of the average height of the surrounding trees). Gaps were either natural or manmade, were always composed of natural regeneration of all four species, and had not been thinned or otherwise influenced by management. We harvested the saplings from the central part of these gaps. We attempted to harvest both live and dead saplings in equal numbers from the five locations, but larger gaps finally contributed slightly more live and dead individuals.

The study area has a humic podzol soil of coarse sand with low water-holding capacity and nutrient content (Anonymous 1975). Even though root competition will occur on these soils, in this paper we focus solely on the competition for light during the self-thinning phase. 
Long-term annual temperature at the nearest weather station is $9.4^{\circ} \mathrm{C}$, the warmest month is July with $17.2^{\circ} \mathrm{C}$ on average, the coldest is February with $-0.6^{\circ} \mathrm{C}$. Average annual precipitation amounts to $860 \mathrm{~mm}$, more or less equally distributed over the year (KNMI 2005).

\section{Data collection}

We used tree-ring analysis to study responses of saplings and trees to environmental conditions (Pollmann 2003; Rozas 2003), and to assess mortality as a function of previous growth (Bigler and Bugmann 2004; Bigler et al. 2004). As radial growth is strongly related to biomass increment in the four studied species (Dekker et al. 2007, 2008) it can be taken as an indicator of whole tree growth.

The live and dead saplings were harvested in the spring and summer of 2005. The live saplings were collected randomly from different canopy positions that were used as a proxy for light availability. For this we used a five-point Canopy Position Index (CPI) with: (1) the tree does not receive direct light, (2) the tree receives direct lateral light, (3) the tree receives direct overhead light on part of the crown, (4) the tree receives full overhead light on the whole crown and (5) the tree has an emergent crown that receives light from all directions (Clark and Clark 1992). This ordinal-scale visual estimation is used in both tropical and temperate forests (Jennings et al. 1999) and provides sufficient accuracy to differentiate between broad ecological strategies of species (Poorter et al. 2005; Sheil et al. 2006). We harvested six live individuals per species per CPI class, yielding a total of 120 live saplings.

The dead saplings were collected together with the live ones. We selected individuals that were fully overtopped, did not have an obvious alternative cause of death (e.g. damage) and therefore most likely died from light starvation, and showed signs of having recently died. 'Recently' was evaluated by checking whether a tree still had the remains of a crown (i.e. fine branches, not leaves), had to some extent flexible twigs, did not have an advanced level of stem rot at ground level, and did not have its stem and branches covered with algae, mosses or fungi. Together, such characteristics are reasonably accurate in discerning between trees that recently died or that died much earlier (Kobe et al. 1995; Kobe and Coates 1997). In the case of deciduous trees (Silver birch and Japanese larch) an individual was considered potentially alive, and was thus rejected, when it still had non-blackened buds and/or if the fine twigs were very flexible and moist inside. Based on the ages of the live and dead individuals (see Table 1 and "Results") we estimated that dead saplings in most cases died $<5$ years ago. As we deliberately investigated saplings under field conditions, both the exact time and cause of death will to some level remain unclear.

After recording CPI, height $(\mathrm{m})$, and $\mathrm{dbh}(\mathrm{cm})$ we cut down the live and dead trees and took a stem disc at ground level. These discs were air dried and sanded (up to 800 grit) to obtain a smooth surface so that tree-ring boundaries were clearly detectable. Tree-ring widths were measured with a precision of 1/100 $\mathrm{mm}$ along two perpendicular radii using a LinTab measuring stage from RinnTec. The two tree-ring series per tree were subsequently averaged. A number of stem discs from the dead individuals showed an advanced level of decay, despite our selection criteria, making it impossible to accurately measure the tree rings. These samples were discarded, leaving a total of 158 dead saplings.

Finally, we made an empirical estimation of mortality by counting all dead and live individuals of the four species along three $30 \mathrm{~m} \times 1 \mathrm{~m}$ transects (oriented NW-SE, NESW and E-W) in the largest of the five gaps. In total we counted 534 individuals which we used to calculate species-specific fractions of dead individuals. This can be taken as an estimate of the 5-year mortality rate since we applied the same criteria as described above to identify trees that recently died.

Data analysis

\section{Radial growth}

We used the single tree-ring series to construct a mean curve (chronology) per species for both live and dead individuals by averaging the tree-ring widths for each year (cf. Orwig and Abrams 1995; Pollmann 2003; Rozas 2003; cf. Bigler and Bugmann 2004). To document the variation

Table 1 Sample sizes and averages per species for dbh, height and age

\begin{tabular}{|c|c|c|c|c|c|c|c|c|}
\hline \multirow[t]{2}{*}{ Species } & \multicolumn{2}{|l|}{$n$} & \multicolumn{2}{|c|}{ DBH (cm) } & \multicolumn{2}{|c|}{ Height (m) } & \multicolumn{2}{|l|}{ Age (y) } \\
\hline & Dead & Alive & Dead & Alive & Dead & Alive & Dead & Alive \\
\hline Silver birch & 40 & 30 & $2.3(0.4)$ & $4.2(1.4)$ & $4.5(1.3)$ & $7.0(1.2)$ & $8.6(1.4)$ & $11.8(1.8)$ \\
\hline Douglas fir & 36 & 30 & $2.7(0.7)$ & $3.9(1.2)$ & $3.7(0.8)$ & $4.0(0.9)$ & $8.4(1.6)$ & $11.5(2.1)$ \\
\hline Scots pine & 35 & 30 & $2.9(0.8)$ & $4.0(1.3)$ & $3.9(0.9)$ & $4.2(0.8)$ & $8.1(1.7)$ & $11.5(1.5)$ \\
\hline Japanese larch & 47 & 30 & $2.0(0.7)$ & $4.5(1.8)$ & $3.8(1.2)$ & $5.6(1.6)$ & $8.8(1.8)$ & $13.3(1.1)$ \\
\hline
\end{tabular}

Values in brackets refer to standard deviation 
in radial growth through time these chronologies were plotted together with the single tree-ring series. For the live saplings of each species we created a mean curve per crown position at harvest (CPI). Interpretation of the annual variation in relation to environmental factors, i.e. weather conditions, was beyond the scope of this study. Such analyses were constrained by the limited length of the time series as well as the fact that radial growth in selfthinning saplings is mostly determined by light competition (Wyckoff and Clark 2002). Instead, we focussed on the general growth level and the growth trend, separated in initial growth (first formed rings around the pith) and final growth (last formed five rings before death or harvest). We finally calculated average diameter and height-growth rate by dividing the dbh and tree height at harvest by the age of the tree. Differences between species were subsequently tested with a non-parametric Kruskal-Wallis test.

\section{Initial growth, final growth and crown position}

As a crown position only applies to the moment of harvest and does not necessarily apply to the whole life span of a sapling, we checked whether a dominant or suppressed tree at the time of harvest always displayed a high or a low radial growth level. To do this, we ranked our data and for each species selected the 12 trees that displayed the highest growth in the first 3 years after establishment, as well as the 12 trees that displayed the lowest growth after establishment, so 24 out of the 30 live trees per species $(80 \%)$ were part of this analysis. This avoids generating results based only on 'extreme' trees. A period of 3 years averages out random single-year fluctuations but is short enough to indicate a fast or slow growth start for a seedling. For each of the four species we tested whether initial and final growth, as well as CPI, differed between the two groups using a Kruskal-Wallis test. We additionally correlated initial growth with final growth by calculating Pearson's $r$. We also did this for crown position at harvest by calculating Spearman's rho. A positive relationship would indicate a trend in which trees that have a fast start continue to profit from this head start and end up high in the canopy, thereby linking CPI at harvest to a tree's growth history.

\section{Average 5-year final growth}

For each individual we calculated the average radial growth of the last 5 years prior to death or harvest. We used this for the analysis of growth under different light availability, as well as for the analysis of mortality. The choice for this 5 -year period was made after doing a Wilcoxon rank sum test for a difference in average growth between live and dead individuals, using the growth over the last 5, 4 and 3 years, respectively. The analysis with a 5-year period had the highest significance, and therefore yields the clearest differences in growth between live and dead individuals. Results using the 3,4 and 5-year periods were very similar however, so the choice of period is not critical. This was also noted by Wyckoff and Clark (2002) and Kobe et al. (1995) who similarly used a 5 -year average growth period. We performed a Kruskal-Wallis test to analyse differences in radial growth within species, depending on CPI.

\section{Modelling and estimation of mortality}

To analyse the relationship between radial growth and mortality we applied the model of Kobe et al. (1995) and Kobe and Coates (1997). It is based on a Maximum Likelihood method that estimates species-specific parameters of functions that model a sapling's probability of mortality based on recent growth. Mortality probability in our case covers a period of 5 years, our limit to trees that recently died.

Let $m(g)$ represent the probability of mortality at a given growth rate $g$, and $h(g)$ the probability density of all growth rates. The expectation of mortality $\bar{U}$ is then given by $\bar{U}=$ $\int_{0}^{\infty} m(g) h(g) d g$ Let $D$ denote the number of dead saplings which were found in a transect of $N$ individuals, $Q$ the number of dead stems, indexed by $i$, for which the growth rate is available, and $R$ the number of live stems, indexed by $j$. Kobe et al. (1995) show that the likelihood $L$ for such a dataset is given by

$$
\begin{aligned}
L= & \left(\bar{U}^{D}\right)(1-\bar{U})^{N-D} \cdot \prod_{i=1}^{Q} \frac{m\left(g_{i}\right) h\left(g_{i}\right)}{\bar{U}} \\
& \cdot \prod_{j=1}^{R} \frac{\left\{1-m\left(g_{j}\right)\right\} h\left(g_{j}\right)}{1-\bar{U}}
\end{aligned}
$$

Maximum likelihood can be employed to estimate parameters of the functions $m(g)$ and $h(g)$. We used a gamma density with parameters $\alpha$ and $\beta$ to specify $h(g)$ :

$h(g)=\frac{g^{\alpha-1} \beta^{\alpha} e^{-g / \beta}}{\Gamma(\alpha)}$

For the probability of mortality $m(g)$ we used an exponential decay with parameter $A$ and $B$ :

$m(g)=A e^{-B g}, \quad$ where $0<A \leq 1$ and $B>0$

These are the same functional forms as used by Kobe et al. (1995), only the gamma density is parameterised differently. The expectation of mortality can then be written in closed form $\bar{U}=A(B \beta+1)^{-\alpha}$.

In fitting Eq. 1 per species the likelihood $L$ is maximised of obtaining the current dataset as a function of (1) the probability of encountering $Q$ dead saplings and $R$ live saplings, (2) the product of the probability densities that a dead sapling had growth history $g_{i}$ prior to death, and (3) 
the product of the probability densities that a live sapling had growth history $g_{j}$.

Our main interest was in the parameters $A$ and $B$ of the exponential mortality function which contain information on differences in growth-related mortality between species. We tested whether $A=1$, i.e. whether zero growth implies certain death. Note that $A=1$ is on the boundary of parameter space and an ordinary likelihood ratio test is not available. We therefore used a non-parametric bootstrap test which employs the observed data to approximate the unknown sampling distribution of a test statistic by sampling observations with replacement (Efron and Tibshirani 1994). The test statistic used was the difference in log-likelihood for the model with $A=1$ and the model with $0<A \leq 1$, and we used 1,000 bootstrap samples. A single bootstrap sample consisted of three parts, all drawn with replacement: a sample of size $Q$ from the dead trees, a sample of size $R$ from the live trees, and a sample of size $N$ from the transect data. The non-parametric bootstrap, with 1,000 bootstrap samples, was also employed to create $95 \%$ confidence intervals for the parameter estimates, and thus for the mortality curves.

\section{Results}

Radial growth at ground level of live and dead saplings

All live saplings experienced a growth decline over time after an initial period of high growth. On top of this agerelated growth trend, the relative position of the mean curves per CPI show a growth reduction when trees have a less favourable crown position, with the exception of Douglas fir (Fig. 1). Overall, growth levels across species were broadly in the same range. Fully overtopped individuals of the shadetolerant Douglas fir, however, on average never reached the low-growth levels $\left(<1 \mathrm{~mm}\right.$ year $\left.^{-1}\right)$ of comparable individuals of the other species.

Table 1 presents the average dbh, height and age for both live and dead individuals per species. For the live saplings we checked for differences in height and diameter growth, across CPIs. Diameter growth rates (in $\mathrm{cm}$ year $^{-1} \pm$ s.d.) for Silver birch, Douglas fir, Scots pine and Japanese larch were $0.36( \pm 0.14), 0.34( \pm 0.10), 0.35$ $( \pm 0.11)$ and $0.33( \pm 0.13)$ respectively, and were not significantly different $(p=0.823)$. Average height growth rates (in $\mathrm{m} \mathrm{y}^{-1} \pm$ s.d.) significantly differed between species $(p<0.0001)$ and were $0.61( \pm 0.16), 0.36( \pm 0.09)$, $0.37( \pm 0.06)$ and $0.42( \pm 0.11)$, respectively. Dead individuals on average grew significantly slower prior to death $(p<0.05)$ than did the harvested live individuals in all species except Japanese larch $(p=0.648)$.

In Douglas fir, the differentiation between individuals with respect to their final crown position (CPI) occurred in approximately the first 6 years of their life (Fig. 1). After that, growth between trees of different CPI (measured at harvest) did not differ systematically. The differentiation according to CPI in Silver birch and Scots pine was more consistent over the whole life span, with the exception of the initial years after establishment. In Japanese larch, growth with respect to current CPI was separated into two groups. Individuals that received high light (CPI 4 and 5) by far outgrew individuals that received average to low light (CPI 1 to 3 ).

The mean radial growth curves of fully overtopped $(\mathrm{CPI}=1)$ individuals of Silver birch, Scots pine and Japanese larch showed a similar growth pattern as those of the dead, light-starved individuals (Fig. 1). In Douglas fir, however, fully overtopped individuals had a constant growth rate, whereas individuals that died showed a gradual decline in growth rate starting approximately 8 years prior to their death. Dead trees of Silver birch, Scots pine and Japanese larch all showed a strong growth decline over time. Scots pine, however, displayed a highly erratic growth prior to death, whereas the long and flat tail in Japanese larch suggests that this species can persist at low growth for some time. Overall, growth reduction was a gradual and long-term process in all species and mortality occurred when radial growth was consistently reduced to approximately $0.5 \mathrm{~mm}$ year ${ }^{-1}$.

The data further show that variation in past growth can be large in both live and dead individuals of all species (Fig. 1). Important to note is that at higher ages fewer trees remain to make up the mean curves, which might cause sudden fluctuations towards the end of the series.

Correlations between initial and final growth and crown position

The two groups of low and high initial growth differed significantly, showing that newly established individuals can have a wide range in growth (Fig. 1; Table 2). In Silver birch and Japanese larch, high initial growth correlated with high growth later in life. This correlation however was rather weak and did not lead to a significant difference in radial growth between the two groups prior to harvest. This suggests that the initial differences in radial growth leveloff over time.

For all species except Scots pine, there was a significant correlation between initial growth and CPI at harvest, indicating that trees with a high initial growth end up high in the canopy (high CPI) and vice versa. There was no difference in the average age per CPI class for all species except for Japanese larch, which had more young trees in CPI 2 (average age 11.8 years, in the other classes this ranges from 13.5 to 13.8 years) causing an overall significant difference $(p=0.021)$. When comparing the groups 
Fig. 1 Individual growth curves (grey lines) and middle curves (black lines). For the live saplings (left column) a middle curve is given for all individuals of a given crown position (CPI), for the dead individuals (right column) a single overall middle curve is drawn. Note that at higher ages fewer trees remain to make up the middle curves, which therefore display sudden fluctuations towards the end of the growth series
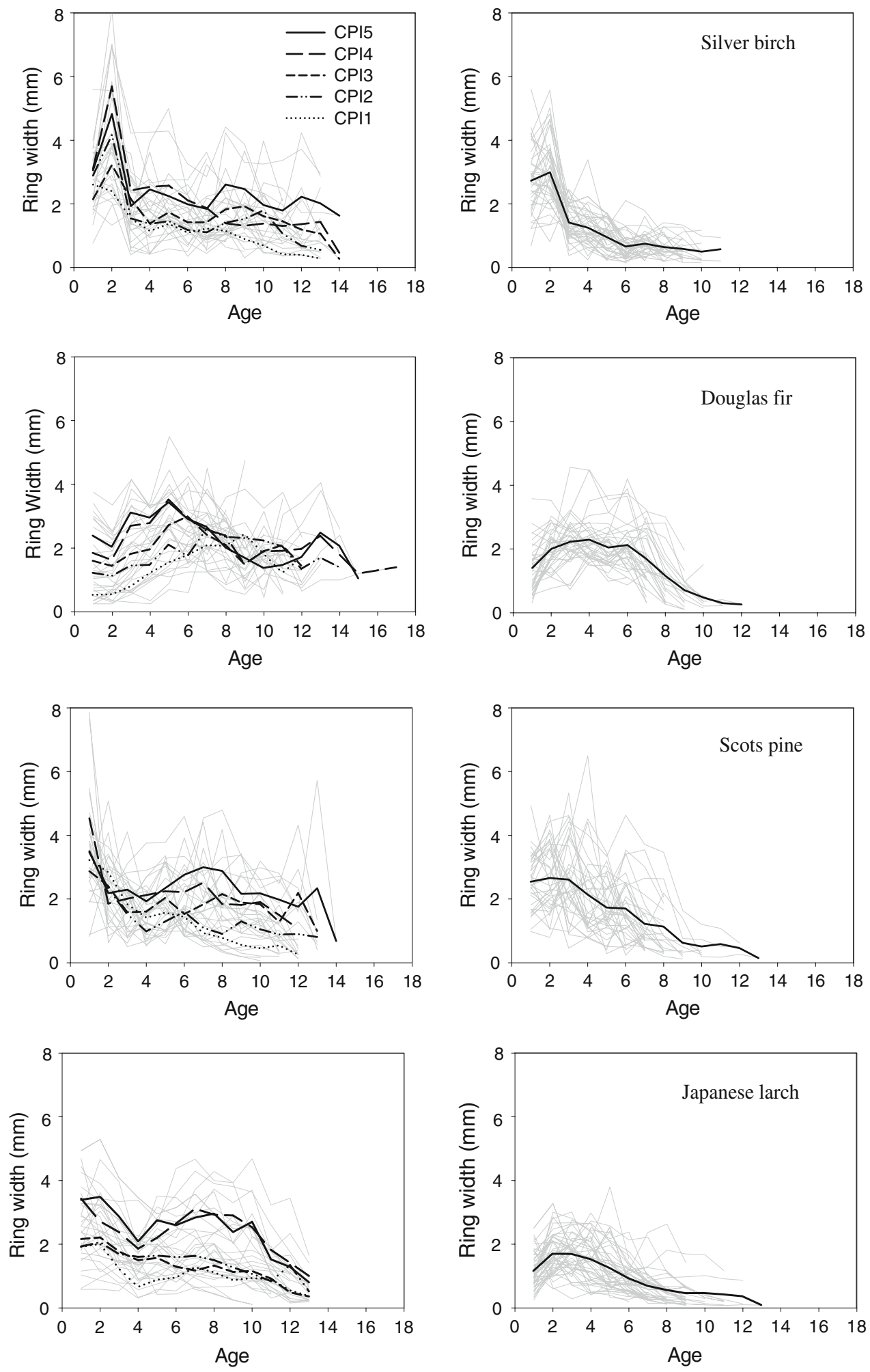

of high and low initial growth, CPI at harvest was significantly different for Douglas fir and Japanese larch (Table 2). In Scots pine, initial growth is similar for all trees, and differentiation in growth as related to CPI starts only approximately 4 years after establishment.
Average radial growth at ground level over the last 5 years

Average radial growth over the last 5 years, used as input in the mortality model, was reduced in the lower canopy 
Table 2 Initial and final radial growth rates (at ground level, 3 year average in mm year ${ }^{-1}$ ) and final average CPI for two groups: a high initial growth group, and a low initial growth group

\begin{tabular}{|c|c|c|c|c|c|}
\hline Species & Parameter & $\begin{array}{l}\text { Low initial } \\
\text { growth group }\end{array}$ & $\begin{array}{l}\text { High initial } \\
\text { growth group }\end{array}$ & $\begin{array}{l}p \text {-value of } \\
\text { the difference }\end{array}$ & $\begin{array}{l}\text { Correlation } \\
\text { ( } p \text {-value) }\end{array}$ \\
\hline \multirow[t]{3}{*}{ Silver birch } & Initial growth & 2.0 & 3.8 & $<0.0001$ & n.a. \\
\hline & Final growth & 1.3 & 1.7 & 0.299 & $0.38(0.038)$ \\
\hline & CPI harvest & 2.3 & 3.4 & 0.077 & $0.42(0.022)$ \\
\hline \multirow[t]{3}{*}{ Douglas fir } & Initial growth & 0.67 & 2.7 & $<0.0001$ & n.a. \\
\hline & Final growth & 2.1 & 1.8 & 0.371 & $-0.31(0.100)$ \\
\hline & CPI harvest & 1.9 & 3.8 & 0.002 & $0.68(<0.001)$ \\
\hline \multirow[t]{3}{*}{ Scots pine } & Initial growth & 2.0 & 3.2 & $<0.0001$ & n.a. \\
\hline & Final growth & 1.4 & 1.5 & 0.707 & $-0.13(0.478)$ \\
\hline & CPI harvest & 3.2 & 3.4 & 0.595 & $0.07(0.710)$ \\
\hline \multirow[t]{3}{*}{ Japanese larch } & Initial growth & 1.4 & 3.3 & $<0.0001$ & n.a. \\
\hline & Final growth & 0.7 & 1.1 & 0.074 & $0.40(0.028)$ \\
\hline & CPI harvest & 2.3 & 3.6 & 0.045 & $0.58(0.001)$ \\
\hline
\end{tabular}

Correlation gives the strength of the relationship between initial growth (irrespective of the two before-mentioned groups) and final growth (Pearson's $r$ ) or CPI (Spearman's rho), respectively; n.a. not applicable

positions (CPI 1\&2) for most species except Douglas fir (Fig. 2). The effect of canopy position was significant for Scots pine $(p=0.001)$ and Japanese larch $(p=0.002)$, but not for Douglas fir $(p=0.977)$. For Silver birch, the data show a declining trend in final growth with lower CPI, but this was not significant $(p=0.144)$ due to the great variability in the dominant canopy positions (CPI 4-5, see Fig. 2).

Average growth prior to death spanned a large range (Fig. 2). For Douglas fir and Scots pine this even encompassed the full range in growth of live individuals. In testing for a difference between dead and live trees (including all CPIs) we found that live individuals of Silver birch $(p<0.0001)$, Japanese larch $(p=0.005)$ and Douglas fir $(p=0.011)$ had experienced significantly higher growth than dead individuals, but this was not the case in Scots pine $(p=0.650)$.

\section{Mortality}

The empirical 5-year mortality estimates from the transect counts (based on the number of dead individuals relative to the total number of individuals per species) were $28 \%$ for Silver birch, $10 \%$ for Douglas fir, 38\% for Scots pine and $16 \%$ for Japanese larch. Estimated mortality functions (see Fig. 3) for Silver birch, Douglas fir and Japanese larch are very similar and reveal a more or less equally declining mortality probability with increasing growth. The curve for Scots pine is very different from the other species, with no relationship between growth and the probability of mortality. We tested whether these results for Scots pine resulted from a lack of fit between growth and mortality, as suggested in Fig. 2. We performed an ad hoc logistic regression between survivorship (a binary response variable indicating whether a tree is dead or alive) and average 5 -year growth (explanatory variable) to generate significance levels. This regression yielded a significant relationship for Silver birch $(p<0.0001)$, Japanese larch $(p=0.001)$ and Douglas fir $(p=0.011)$, but not for Scots pine $(p=0.775)$. Given the lack of a relationship between recent growth and mortality, the fitted mortality function yielded a flat line.

\section{Discussion}

Overall patterns in sapling growth

As plants grow bigger and crowding intensifies all species on average showed a decrease in radial growth at ground level over time, irrespective of canopy position (CPI) was observed. This is most likely caused by the increase in competition, eventually leading to self-thinning (Oliver and Larson 1996). On top of this overall trend, light-demanding (Silver birch and Scots pine) and intermediate (Japanese larch) species responded negatively to a decrease in light availability, whereas the one shade-tolerant species (Douglas fir) maintained a consistent growth level across CPIs. This difference in response was found in both the long-term (tree-ring series, Fig. 1) and the short-term growth (average 5-year growth, Fig. 2).

Initial growth in Douglas fir ultimately determined its crown position at harvest (Fig. 1). This cannot, however, be attributed to light, as the seedling establishment phase is 
Fig. 2 Final radial growth (5 year average) of trees of different status at time of harvest. L1-5 displays final growth of live individuals from different canopy positions, with the index number indicating CPI at harvest. D displays final growth of dead trees
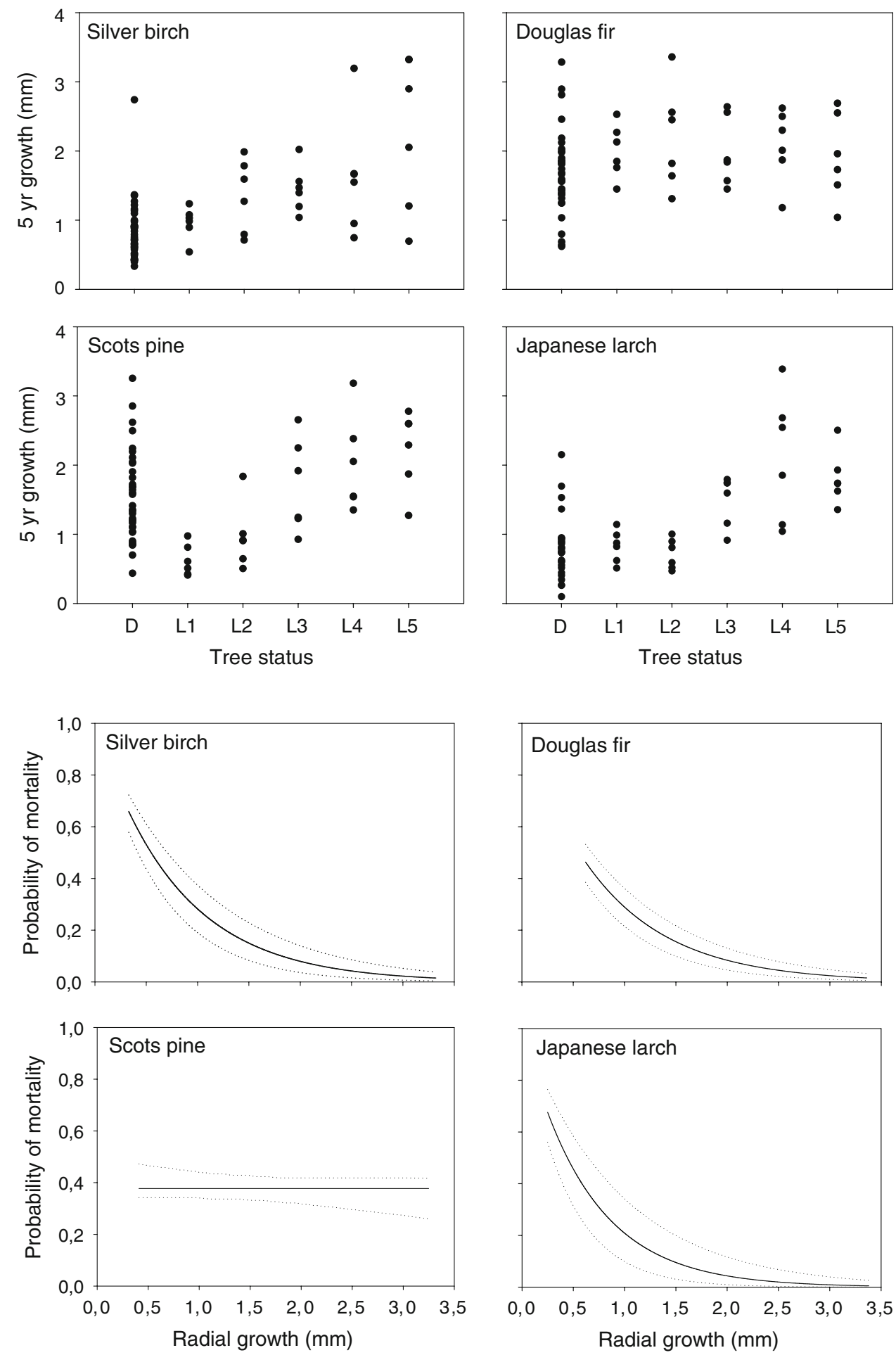

Fig. 3 Mortality curves with 95\% confidence intervals for all species, giving the probability of mortality as a function of radial growth (5 year average). In Scots pine the $A$ parameter is significant $(A=0.378$, s.e. $0.035, p<0.0001)$, for the other species $A=1$. Scots pine furthermore has $B=0$, whereas the other species have a declining probability of mortality with increasing growth. For Silver birch $B=1.256$ (s.e. 0.156), for Douglas fir $B=1.240$ (s.e. 0.121), for Japanese larch $B=1.566$ (s.e. 0.321 ) characterised by full access to light (Oliver and Larson 1996) and overall high-growth rates (Kaelke et al. 2001; Seiwa 2007). Since the average ages did not differ across CPI classes in this species, variation in establishment time cannot explain these results. Most likely genetic makeup and microsite conditions caused the observed differentiation (cf. Huston 1994).
These results for Douglas fir support the general pattern that a seedling's early growth strongly influences its success later in life (Landis and Peart 2005). Our data suggest that individuals with high initial growth after establishment have an increased chance of attaining a canopy, or even emergent, position. This was not the case for Scots pine. Radial growth and height growth are related through 
species-specific height-diameter ratios. These heightdiameter ratios differ between the studied species, resulting in differences in height growth even at a similar diameter growth (Dekker et al. 2007). Height growth subsequently determines a tree's canopy height relative to the surrounding trees. In the case of Scots pine, its high radial growth was not transferred into fast height growth as its height growth was even lower than that of Douglas fir. As Scots pine was unable to grow taller than the other species, it rarely gained a dominant canopy position (after which a negative feedback loop starts in which reduced radial growth is followed by reduced height growth, leading to an even more suppressed canopy position). In the case of the other species, however, saplings generally continued to profit from a head start gained as a seedling, which is especially important for light-demanding species.

Interspecific differences in growth depending on light demand

Our results indicate that differences in performance between species do not occur in high light but rather in low-light conditions (Fig. 2). In high light all species grew at an approximately similar rate, but in low-light Douglas fir outperformed the three other species. These results apparently deviate from other studies which found that under low-light conditions biomass accumulation is at least equal across light-demanding and shade-tolerant species (Walters and Reich 1996, 1999; Poorter 2005), whereas under high-light conditions biomass accumulation is much higher in light-demanding species (Poorter 1999; Portsmuth and Niinemets 2007). This deviation, however, can be explained as follows: in this study we found that-based on whole-life performance-diameter growth rates were not, and height growth rates were significantly different between species. As Dekker et al. (2007) have shown, at equal diameter increment Silver birch and Japanese larch produce significantly more aboveground biomass than Scots pine and Douglas fir. This implies that at the common level of radial growth in high light in this study (for all species averaging around $2 \mathrm{~mm}$ year $^{-1}$ at CPI 4 and 5), Silver birch and Japanese larch produced more biomass than did Douglas fir. It similarly implies that, where Douglas fir outperformed the other species in low light in terms of radial growth, this is likely no longer the case in terms of biomass increment. Therefore, when taking a whole-plant perspective and considering biomass increment rather than radial growth, our results are in line with other research findings.

Scots pine still remains as the 'odd' species since it showed the same height growth as the shade-tolerant Douglas fir, while at the same time it showed a strong positive growth response to light similar to that of a real pioneer like Silver birch (Figs. 1 and 2). So given its reaction to both low light (reduced growth) and high light (lack of fast height growth), and given its high overall and unpredictable mortality, Scots pine does not fit in a growthsurvival trade-off that underlies coexistence. This finding warrants a word of caution for the interpretation of growthsurvival trade-offs in non-natural communities, as is the case in this study. In essence, the growth-survival trade-off should lead to species coexistence by partitioning the light gradient. In communities that have been highly influenced by man through species displacements and compositional changes, secondary successional stages will include species assemblages that are greatly different from those occurring under natural conditions. Under natural conditions, odd species like Scots pine are unlikely to be present since these will have long been outcompeted. Conversely, viewing species within this growth-survival trade-off scheme will enable us to make predictions on the potential of particular species in new assemblages in our ecosystems.

Growth and probability of mortality

We found a significant relationship between recent growth (5-year average) and mortality for all species except Scots pine. In Scots pine the 5-year average growth rates prior to death were too variable to establish a relationship between recent radial growth and the probability of mortality. In fact, growth prior to death spanned the entire range in growth levels of living trees (Fig. 2). There was no effect of sample site in this high variability as data ranges from each of the five sites fully overlapped (data not shown).

Competition for light is considered the main driver of mortality in young and dense self-thinning stands (Oliver and Larson 1996). This originates from the fact that light competition is asymmetric and pre-emptive (Schwinning and Weiner 1998; Weigelt and Jolliffe 2003). Self-thinning in even-aged monospecific stands, for example, is strongly influenced by crown geometry and slenderness (Lonsdale and Watkinson 1983; Weller 1987; Ellison 1989; Franco and Kelly 1998), further supporting the notion that competition for light strongly determines mortality. As the main canopy rises with increasing tree height, individuals that cannot keep up in height growth but which are not sufficiently shade tolerant to survive in the understorey, will die (Oliver and Larson 1996).

In each of our species, however, some individuals died even when displaying an (on average) relatively high radial growth rate in the 5 years prior to death. For Scots pine and Douglas fir we noted an erratic radial growth pattern with abrupt annual changes in a number of individuals, including dominant trees (Fig. 1). Together with the overall trend of a declining growth across species, these patterns suggest other causes than light starvation for mortality. Short-term stresses 
can predispose trees to die if they are already under long-term stress, and can also make trees vulnerable to otherwise relatively harmless afflictions (Pedersen 1998a, b).

In the sampled communities, light deficiency forms a long-term stress factor. Additional short-term stress in the dry sandy soils of our study area can be low water availability during dry years. Pathogen infestation may be a further contributing factor to tree mortality. This particularly holds for Scots pine which is highly susceptible to Needle Cast (Lophodermium spp), especially when growing in dense stands (Schwerdtfeger 1957). With a combination of predisposing, inciting and contributing stresses (Manion 1981) tree mortality will become stochastic and irregular (Kobe 1996; Eid and Tuhus 2001), even in self-thinning stands. We cannot positively confirm such additional agents but our data, which were deliberately collected under field conditions, show that mortality in self-thinning mixed stands is not exclusively driven by light competition.

Mortality analyses for Silver birch, Douglas fir and Japanese larch did not result in significantly different mortality curves (Fig. 3). Average growth levels of these species under different CPIs nevertheless place them on very different parts of this apparently common mortality curve. For example, the consistent growth level of Douglas fir which was on average around $2 \mathrm{~mm}_{\text {year }}{ }^{-1}$ across CPIs, means that this species has an overall 5-year mortality rate of approximately $10 \%$. In dominant individuals of Silver birch (CPI 4 and 5), growing at a similar growth level of $2 \mathrm{~mm}$, mortality also lies around $10 \%$. In Contrast, fully overtopped individuals of this species (CPI 1) have a mortality rate of approximately $30 \%$ as a result of their strongly reduced growth. This illustrates that in Silver birch, as well as Japanese larch, only fast-growing (radial and height growth) individuals that have secured a high canopy position will likely survive. Individuals of all Douglas fir have that same chance, irrespective of light availability during the sapling stage.

In Scots pine we found no relationship between mortality and growth. Results nevertheless suggest that given its strong positive relationship between radial growth and light availability, and its generally low radial and height growth, this species will experience high mortality and will likely be competitively excluded. This is supported by the high empirical mortality counts (38\%, the highest of all species).

This paper described the effect of canopy position on growth and mortality for natural regeneration of four species undergoing self-thinning. The low-nutrient and lowwater site conditions will influence species-specific growth patterns (e.g. the growth rates that give rise to vertical stratification), as well as the competitive pressures and responses of species (e.g. leaf density and susceptibility to light depravation). Even though species behaviour depends on site conditions, such intraspecific autecological variation is rarely drastic. So even if particular values for growth and mortality will change with site conditions, our results, given the broad ecological strategies of the studied species, will likely hold for those locations, where these species can grow and regenerate naturally.

\section{Conclusions}

We conclude the following:

1) In dense mixed stands the competition for light is not the only factor driving self-thinning. Additional shortor long-term stresses offer an important contribution to mortality.

2) For a growth-survival trade-off to contribute to species coexistence, high-light growth in pioneers has to mean that the carbon gained strongly contributes to height extension. This enables vertical stratification and therefore light partitioning.

3) Species in non-natural communities that do not fit in either the high-growth or the high-survival part of the growth-survival trade-off, like in our case Scots pine, suffer high mortality when growing under high competition in natural succession. The growth-survival trade-off therefore also suggests less favourable species mixtures in man-made communities. It is however difficult to evaluate species characteristics in the light of biological trade-offs in non-natural manmade communities, due to the very different evolutionary backgrounds of species.

Open Access This article is distributed under the terms of the Creative Commons Attribution Noncommercial License which permits any noncommercial use, distribution, and reproduction in any medium, provided the original author(s) and source are credited.

\section{References}

Anonymous (1975) Bodemkaart van Nederland 1:50.000, Blad 40 West/Oost Arnhem: www.bodemdata.nl. Accessed 3 Nov 2005

Bigler C, Bugmann H (2004) Predicting the time of tree death using dendrochronological data. Ecol Appl 14(3):902-914. doi: 10.1890/03-5011

Bigler C, Gričar J, Bugmann H, Čufar K (2004) Growth patterns as indicators of impending tree death in silver fir. For Ecol Manage 199:183-190

Burschel P, Huss J (1997) Grundriss des Waldbaus. Parey Buchverlag, Berlin

CABI (2005) Forestry compendium. Wallingford, Cab International

Clark DA, Clark DB (1992) Life history diversity of canopy and emergent trees in a Neotropical rain forest. Ecol Monogr 62(3):315-344. doi:10.2307/2937114 
Dekker M, Van Breugel M, Sterck FJ (2007) Effective height development of four co-occurring species in the gap-phase regeneration of Douglas fir monocultures under nature-oriented conversion. For Ecol Manage 238:189-198. doi:10.1016/j. foreco.2006.10.012

Dekker M, Verkerk PJ, den Ouden J (2008) Target species identity is more important than neighbor species identity. For Ecol Manage 255:203-213. doi:10.1016/j.foreco.2007.09.006

Efron B, Tibshirani RJ (1994) An introduction to the bootstrap. Chapman and Hall, New York

Eid T, Tuhus E (2001) Models for individual tree mortality in Norway. For Ecol Manage 154:69-84. doi:10.1016/S0378-1127 (00)00634-4

Ellison AM (1989) Morphological determinants of self-thinning in plant monocultures and a proposal concerning the role of selfthinning in plant evolution. Oikos 54(3):287-293. doi: $10.2307 / 3565287$

Franco M, Kelly CK (1998) The interspecific mass-density relationship and plant geometry. Proc Natl Acad Sci USA 95:78307835. doi:10.1073/pnas.95.13.7830

Grime JP (2001) Plant strategies, vegetation processes, and ecosystem properties. Wiley, Chichester

Huston MA (1994) Biological diversity: the coexistence of species in changing landscapes. Cambridge University Press, Cambridge

Jennings S, Brown ND, Sheil D (1999) Assessing forest canopies and understorey illumination: canopy closure, canopy cover and other measures. Forestry 72(1):59-73. doi:10.1093/forestry/ 72.1 .59

Kaelke CM, Kruger EL, Reich PB (2001) Trade-offs in seedling survival, growth, and physiology among hardwood species of contrasting successional status along a light-availability gradient. Can J For Res 31:1602-1616. doi:10.1139/cjfr-31-9-1602

King DA (1994) Influence of light level on the growth and morphology of saplings in a Panamanian forest. Am J Bot 81(8):948-957. doi:10.2307/2445287

Kitajima K (1994) Relative importance of photosynthetic traits and allocation patterns as correlates of seedling shade tolerance of 13 tropical trees. Oecologia 98:419-428. doi:10.1007/BF00 324232

Kitajima K, Poorter L (2008) Functional basis for resource niche partitioning by tropical trees. In: Carson WP, Schnitzer SA (eds) Tropical forest community ecology. Oxford, Blackwell

KNMI (2005) Langjarige gemiddelden en extremen, tijdvak 1971-2000: http://www.knmi.nl/klimatologie/normalen1971-2000/ element_gegevens.html. Accessed 3 Nov 2005

Kobe RK (1996) Intraspecific variation in sapling mortality and growth predicts geographic variation in forest composition. Ecol Monogr 66(2):181-201. doi:10.2307/2963474

Kobe RK, Coates KD (1997) Models of sapling mortality as a function of growth to characterize interspecific variation in shade tolerance of eight tree species of northwestern British Columbia. Can J For Res 27:227-236. doi:10.1139/cjfr-27-2-227

Kobe RK, Pacala SW, Silander JA, Canham CD (1995) Juvenile tree survivorship as a component of shade tolerance. Ecol Appl 5(2):517-532. doi:10.2307/1942040

Kohyama T (1993) Size-structured tree populations in gap-dynamic forest-the forest architecture hypothesis for the stable coexistence of species. J Ecol 81:131-143. doi:10.2307/2261230

Kohyama T, Suzuki E, Partomihardjo T, Yamada T, Kubo T (2003) Tree species differentiation in growth, recruitment and allometry in relation to maximum height in a Bornean mixed dipterocarp forest. J Ecol 91:797-806. doi:10.1046/j.1365-2745.2003. 00810.x

Landis RM, Peart DR (2005) Early performance predicts canopy attainment across life histories in subalpine forest trees. Ecology 86(1):63-72. doi:10.1890/03-0848
Lin J, Harcombe PA, Fulton MR, Hall RW (2002) Sapling growth and survivorship as a function of light in a mesic forest of southeast Texas, USA. Oecologia 132:428-435. doi:10.1007/s00442-0020986-5

Lonsdale WM, Watkinson AR (1983) Plant geometry and selfthinning. J Ecol 71:285-297. doi:10.2307/2259977

Manion PD (1981) Tree disease concepts. Prentice-Hall, New Jersey

Mayer H (1992) Waldbau auf soziologisch-ökologischer Grundlage. Gustav Fischer Verlag, Stuttgart

Oliver CD, Larson BC (1996) Forest stand dynamics. Wiley, New York

Orwig DA, Abrams MD (1995) Dendroecological and ecophysiological analysis of gap environments in mixed-oak understoreys of northern Virginia. Funct Ecol 9(6):799-806. doi:10.2307/2389977

Osada N, Tateno R, Hyodo F, Takeda H (2004) Changes in crown architecture with tree height in two deciduous tree species: developmental constraints or plastic response to the competition for light? For Ecol Manage 188:337-347. doi:10.1016/j.foreco. 2003.08.003

Pedersen BS (1998a) Modeling tree mortality in response to shortand long-term environmental stresses. Ecol Modell 105:347351. doi:10.1016/S0304-3800(97)00162-2

Pedersen BS (1998b) The role of stress in the mortality of midwestern oaks as indicated by growth prior to death. Ecology 79(1):79-93

Pollmann W (2003) Stand structure and dendroecology of an oldgrowth Nothofagus forest in Conguillo National Park, south Chile. For Ecol Manage 176:87-103. doi:10.1016/S0378-1127 (02)00279-7

Poorter L (1999) Growth responses of 15 rain-forest tree species to a light gradient: the relative importance of morphological and physiological traits. Funct Ecol 13:396-410. doi:10.1046/j. 1365-2435.1999.00332.x

Poorter L (2005) Resource capture and use by tropical forest seedlings and their consequences for competition. In: Burslem DFRP et al (eds) Biotic interactions in the Tropics: their role in the maintenance of species diversity. Cambridge University Press, Cambridge

Poorter L, Arets EJJM (2003) Light environment and tree strategies in a Bolivian tropical moist forest: an evaluation of the light partitioning hypothesis. Plant Ecol 166:295-306. doi:10.1023/A: 1023295806147

Poorter L, Kitajima K (2007) Carbohydrate storage and light requirements of tropical moist and dry forest tree species. Ecology 88(4):1000-1011. doi:10.1890/06-0984

Poorter L, Bongers F, Sterck FJ, Wöll H (2003) Architecture of 53 rain forest tree species differing in adult stature and shade tolerance. Ecology 84(3):602-608. doi:10.1890/0012-9658 (2003)084[0602:AORFTS]2.0.CO;2

Poorter L, Bongers F, Sterck FJ, Wöll H (2005) Beyond the regeneration phase: differentiation of height-light trajectories among tropical tree species. J Ecol 93:256-267. doi:10.1111/ j.1365-2745.2004.00956.x

Portsmuth A, Niinemets Ü (2007) Structural and physiological plasticity in response to light and nutrients in five temperate deciduous woody species of contrasting shade tolerance. Funct Ecol 21:61-77. doi:10.1111/j.1365-2435.2006.01208.x

Reich PB, Wright IJ, Cavender-Bares J, Craine JM, Oleksyn J, Westoby M, Walters MB (2003) The evolution of plant functional variation: traits, spectra, and strategies. Int J Plant Sci 164(3):143-164. doi:10.1086/374368

Rozas V (2003) Regeneration patterns, dendroecology, and forest-use history in an old-growth beech-oak lowland forest in Northern Spain. For Ecol Manage 182:175-194. doi:10.1016/S0378-1127 (03)00070-7

Schwerdtfeger F (1957) Die Waldkrankheiten, 2nd edn. Paul Parey, Hamburg 
Schwinning S, Weiner J (1998) Mechanisms determining the degree of size asymmetry in competition among plants. Oecologia 113:447-455. doi:10.1007/s004420050397

Seiwa K (2007) Trade-offs between seedling growth and survival in deciduous broadleaved trees in a temperate forest. Ann Bot (Lond) 99:537-544. doi:10.1093/aob/mcl283

Sheil D, Salim A, Chave J, Vanclay J, Hawthorne WD (2006) Illumination-size relationships of 109 coexisting tropical forest tree species. J Ecol 94:494-507. doi:10.1111/j.1365-2745. 2006.01111.x

Sterck FJ, Bongers F (2001) Crown development in tropical rain forest trees: patterns with tree height and light availability. J Ecol 89:1-13. doi:10.1046/j.1365-2745.2001.00525.x

Sterck FJ, Martinéz-Ramos M, Dyer-Leal G, Rodríquez-Velazquez J, Poorter L (2003) The consequences of crown traits for the growth and survival of tree saplings in a Mexican lowland rainforest. Funct Ecol 17:194-200. doi:10.1046/j.1365-2435. 2003.00729.x
Walters MB, Reich PB (1996) Are shade tolerance, survival, and growth linked? Low light and nitrogen effects on hardwood seedlings. Ecology 77(3):841-853. doi:10.2307/2265505

Walters MB, Reich PB (1999) Low-light carbon balance and shade tolerance in the seedlings of woody plants: do winter deciduous and broad-leaved evergreen species differ? New Phytol 143:143-154. doi:10.1046/j.1469-8137.1999.00425.x

Weigelt A, Jolliffe P (2003) Indices of plant competition. J Ecol 91:707-720. doi:10.1046/j.1365-2745.2003.00805.x

Weller DE (1987) Self-thinning exponent correlated with allometric measures of plant geometry. Ecology 68(4):813-821. doi: $10.2307 / 1938352$

Westoby M (1998) A leaf-height-seed (LHS) plant ecology strategy scheme. Plant Soil 199:213-227. doi:10.1023/A:1004327224729

Wyckoff PH, Clark JS (2002) The relationship between growth and mortality for seven co-occurring tree species in the southern Appalachian Mountains. J Ecol 90:604-615. doi:10.1046/j. 1365-2745.2002.00691.x 